\title{
Memoriais de formação: o dizer da experiência na escrita ou a escrita como experiência
}

\author{
Memorials of education: the mean of experience \\ in writing or writing as experience \\ Memorias de formación: qué decir de la experiencia
en la escrita o la escrita como experiencia
}

\author{
ANALICE DUTRA PILlaR* \\ GILVÂNIA MAURÍcIO DiAS DE PONTES**
}

\begin{abstract}
RESUMO - Este trabalho, que aborda interfaces entre estética, arte e escrita, é parte de uma pesquisa que busca evidenciar relações entre experiências estéticas e prática docente com linguagens artísticas, narradas em memoriais produzidos por professores da educação da infância, no Curso de Especialização em Ensino de Arte e Educação Física na Infância, desenvolvido pelo Paideia/UFRN. Trata-se de uma pesquisa qualitativa em que a metodologia assumiu, como princípios e estratégias de análise, a semiótica discursiva e alguns pressupostos da pesquisa (auto)biográfica, referentes à produção de narrativas como experiência de formação. $\mathrm{O}$ corpus foi composto por cinco memoriais de formação. Na análise dos memoriais, procurou-se identificar como as experiências estéticas dos professores estavam presentes nos discursos que teciam sobre sua prática. Durante a pesquisa, o processo de leitura das narrativas dos professores conduziu à tessitura de relações entre escrita, estética e arte como experiência de produção de sentidos e de expressão de si.
\end{abstract}

Palavras-chave - Escrita. Experiência estética. Arte educação.

\begin{abstract}
This article, which addresses interfaces among aesthetics, art and writing, is derived from a research that seeks to show the relationship between aesthetic experiences and the teaching practice with artistic languages, narrated in memorials produced by childhood education teachers in the Specialization Course in Art Education and Physical Education in Childhood, developed by Paideia/UFRN. This is a qualitative research in which the methodology assumed, as principles and strategies of analysis, the discursive semiotics and some assumptions of the (auto)biographical research, related to narrative productions as formation experience. The corpus was composed by five formation memorials. In the analysis of the memorials, we tried to identify how the teachers' aesthetic experiences were present in the discourses they wove about their practice. During the research, the process of reading the narratives of the teachers led to the enchainment of relations between writing, aesthetics and art as experience of creation of meaning and expressions of self.
\end{abstract}

Keywords - Writing. Aesthetic experience. Art education.

RESUMEN - Este artículo, que trata de interfaces entre la estética, el arte y la escrita, es oriundo de una investigación que busca evidenciar relaciones entre experiencias estéticas y la práctica docente con lenguajes artísticos, narrados en memorias producidas por profesores de la educación de la infancia, en el Curso de Especialización en Educación Artística y Educación Física en la Infancia, desarrollado por el Paideia/UFRN. Se trata de una investigación cualitativa en que la metodología asumió, como principios y estrategias de análisis, la semiótica discursiva y algunos presupuestos de la investigación (auto)biográfica, referentes a la producción de narrativas como experiencia de formación. El corpus se compuso de cinco memorias de formación. En el análisis de las memorias, se procuró identificar cómo las experiencias estéticas de los profesores estaban presentes en los discursos que tejían sobre su práctica. Durante la investigación, el proceso de lectura de las narrativas de los profesores condujo a la composición de relaciones entre la escrita, la estética y el arte como experiencia de producción de sentidos y de expresión de sí. Palabras-clave - Escrita. Experiencia estética. Arte educación.

\footnotetext{
*Doutora em Artes pela Universidade de São Paulo (São Paulo, SP, Brasil) e professora na Universidade Federal do Rio Grande do Sul (Porto Alegre, RS, Brasil).E-mail: <analicedpillar@gmail.com>.

**Doutora em Educação pela Universidade Federal do Rio Grande do Sul (Porto Alegre, RS, Brasil) e professora na Universidade Federal do Rio Grande do Norte (Natal, RN, Brasil).E-mail: <gil@ufrnet.br>.
} 
Este texto é oriundo de uma pesquisa cujo enfoque é a produção de sentidos dos professores para a relação entre suas experiências estéticas e a prática docente. A pesquisa aborda a experiência estética através das escolhas que professores de Educação Infantil e anos iniciais do Ensino Fundamental ressaltam em seus memoriais. Este artigo traz uma aproximação não linear às práticas de escritura para falar sobre as práticas sociais que ampliam o entendimento de escrita para além da grafia de letras, incluindo as relações de produção que envolvem essa prática, como, por exemplo, as relações com a oralidade e com a visualidade que se fazem presentes no texto escrito.

Em Escritura como invención, escritura ${ }^{1}$ como expresión, Armando Petrucci (1999) afirma que toda escrita é habitualmente considerada um meio de comunicação, mas que toda escrita é também feita de signos. Além disso, as escrituras, como maneiras de escrever vivenciadas pelos produtores de escrita, em determinado tempo histórico, têm como aspecto significativo para sua análise a observação dos instrumentos, dos materiais e das técnicas adotadas na produção do escrito. Depreendemos dessa afirmação que a leitura da escrita envolve um olhar sobre o conteúdo que é enunciado e sobre a forma como tal conteúdo é enunciado, ou seja, sobre o conteúdo e a expressão presentes nos testemunhos escritos, inclusive, em sua materialidade de produção.

Nessa relação de criação de escrita há os autores de testemunhos escritos, os produtores de escrita. Petrucci (1999, p. 119) observa que ter como foco de estudo os contextos de produção e quem produz a escrita, "nos lleva inevitablemente a estudiar a los operadores de la escritura, los hombres y mujeres que, en los dos ámbitos, escriben y producen testimonios escritos de su cultura material, sus aptitudes y sus capacidades técnica, su manera de ser e actuar".

Suportes, figuratividade e composição estética constituem dimensões das práticas de escritura que podemos tomar como ponto de partida para a análise do objeto de escrita. A reflexão sobre a materialidade da escrita pode possibilitar pensar a escrita, vislumbrando a relação entre interpretação dos processos, das práticas e dos gestos envolvidos nas escolhas dos meios de expressão.

Petrucci (1999) salienta que, para alcançar a finalidade figurativa, os produtores de escrita exaltam os aspectos estéticos por meio da valorização de elementos ornamentais e decorativos. A produção figurativa está relacionada à cultura, à educação gráfica e ao ambiente ao qual se dirige. O complexo figurativo da escritura traços, curvas, desenhos - conta a história das práticas de escrita. Tais práticas mobilizam tanto as referências culturais de quem escreve como a intencionalidade, a qual pressupõe um leitor, quanto a materialidade dos objetos de escrita
Reflexões sobre o lugar do leitor na produção de sentidos para as práticas de escrita são encontradas também no texto Ler: uma operação de caça, de Michel de Certeau (1994, p. 263) que salienta: "[...] desde a leitura da criança até a do cientista ela é precedida e possibilitada pela comunicação oral, inumerável 'autoridade' que os textos não citam quase nunca". Assim, a prática de leitura é um ato comunicativo que envolve mais do que decifrar o escrito. É um ato que diz respeito também às relações contextuais de produção dessas leituras, entre elas os repertórios orais dos leitores.

O mesmo autor questiona o postulado da passividade do consumo que relaciona a eficácia da produção à inércia do consumidor. Para ele, tal relação referenda-se na ideologia do consumo-receptáculo em que o público é modelado pelos produtos que lhe são impostos e torna-se semelhante ao que recebe. Discordando desse postulado, Certeau propõe a atuação do leitor na produção de sentido e defende o consumo como atividade criadora. O legível - livro, imagem etc. - só tem sentido graças aos leitores, os quais, longe de serem escritores-fundadores de um lugar próprio, são "viajantes; circulam nas terras alheias, nômades caçando por conta própria através dos campos que não escreveram" (1994, p. 269-270).

Sentindo-nos viajantes em terra alheia quando da leitura do texto Escritura como invención, escritura como expresión (PETRUCCI, 1999) fomos impulsionadas à caça de algumas experiências de escrita a partir daquelas mencionadas por Petrucci (1999), cuja tessitura da escrita nos levou a caminhos não lineares em que práticas e produtores de escrita tornaram-se significativos para o estabelecimento de uma reflexão intertextual que nos conduziu aos memoriais de formação escritos por professores.

\section{A ESCRITA EM SEUS SENTIDOS ESTÉTICOS E ARTÍSTICOS}

O início do labirinto, no texto de Armando Petrucci, é marcado pela afirmação de que o texto escrito é composto por um enunciado verbal e por um complexo figurativo que, em si, constitui um enunciado. $\mathrm{Na}$ contemporaneidade, convivem técnicas que vão da escrita manual à videoescrita eletrônica. Buscando acercar-nos da diversidade dos campos de escrita contemporâneos, selecionamos algumas experiências que apresentamos a seguir.

O Livro das perguntas ${ }^{2}$, de Pablo Neruda, obra póstuma que contém 74 perguntas, foi publicado pela primeira vez em 1974, na Argentina; em 2006, foi publicado na Espanha pela editora Media Vaca. A publicação espanhola tem ilustrações do designer e ilustrador Isidro Ferrer, artista gráfico com formação inicial em teatro e que levou 
três anos para criar as ilustrações. Leu toda a obra de Neruda, visitou suas casas, observou suas coleções. Não procurou nem produziu respostas para as perguntas feitas por Neruda; evitou interferir nos poemas. Por meio da reprodução fotográfica de 87 colagens e instalações, Isidro produz suas próprias perguntas em cenários surrealistas que parecem um teatro de marionetes. As perguntas poemas e ilustrações - são convites à reflexão mais do que à produção de respostas.

O Diário de Frida Kahlo, publicado no Brasil, em 1996, pela José Olympio Editora, é um exemplo de escrita íntima, cujo intuito do operador de escrita é estabelecer relações consigo mesmo. Trata-se de um registro de si que foi guardado durante cerca de 40 anos no México; é uma obra tecida com poemas e gravuras coloridas para falar de experiências pessoais de amor, sofrimento, esperança e compromisso político. Nesta obra, estão os refúgios do eu de Frida Kahlo; quando publicada, permitiu aos leitores uma apreciação de sua prática de escrita com arte (KAHLO, 1996), ou, se mudarmos o foco, podemos fazer uma leitura da prática artística como discurso autobiográfico. Nas páginas do diário, escrita e arte se relacionam de forma sincrética na produção de sentido articulada pela artista.

O diário foi escrito durante os dez últimos anos de Frida Kahlo (1944-1954), período em que viveu imobilizada em uma cama por complicações decorrentes de um acidente ocorrido quando tinha 18 anos. A dimensão autobiográfica dessa escrita/arte nos permite ver a produção de sentido de Frida para sua história corporal, sua cultura, suas práticas artísticas. Há a presença de um corpo autobiográfico que fala de si na inter-relação entre linguagens.

Josso (2012, p. 24) ressalta que o corpo é evocado nas narrativas biográficas para falar de percursos de vida em que temas como a saúde do corpo e a morte ocupam lugar importante. De acordo com a autora, as experiências do corpo "ocasionalmente doente, mais ou menos grave ou duradouramente atingido, do corpo definitivamente deficiente, em particular portador de estigmas são fontes de compreensão a posteriori da unidade do ser somatofísico em todos os seus atributos".

Esta relação escrita-corpo é também abordada no filme O livro de cabeceira (1996) em que o diretor Peter Greenaway coloca o enunciatário diante da reflexão sobre o livro metaforizado como corpo ou sobre o corpo como suporte para ler e escrever. No filme, o corpo é um texto a ser lido; o filme é um texto a ser lido; o livro é um corpo a ser lido.

O livro de cabeceira é a narrativa da vida de uma jovem mulher japonesa, Nagiko, no Japão dos anos de 1970, que quando criança vive em seus aniversários um ritual peculiar. Seu pai, que é calígrafo, escreve em seu rosto uma bênção enquanto a sua tia lê um livro de cabeceira escrito há quase mil anos. ${ }^{3} \mathrm{~A}$ personagem cresce entre livros e produção de escrita em corpos nus e, quando adulta, busca alguém que imprima marcas gráficas em seu corpo/livro. Encontra um tradutor inglês do qual passa a ser amante. Com ele, Nagiko se torna, inicialmente, papel (suporte) e, depois, pena, quando escreve no corpo do amante.

A composição do filme é repleta de intertextos citação do antigo livro de cabeceira -, cujos poemas remetem à temática do filme; os textos grafados no corpo da atriz, em caligrafia japonesa, são de autoria do diretor Peter Greenaway numa alusão à relação entre oriente e ocidente. ${ }^{4}$ Para Eduardo Peñuela Cañizal (1993), a intertextualidade é um espaço de reescrita constituído por um mosaico de citações articuladas em função da metáfora. Nesse mosaico, interagem componentes de diferentes códigos.

O filme O livro de cabeceira aborda a caligrafia como produção cultural, difundida no Japão. ${ }^{5}$ A caligrafia, como arte de escrever à mão, com deliberadas e precisas intenções, pode ser repetitiva ou inventiva e inovadora. Como ressalta Petrucci (1999, p. 176), “no Japão, por uma tradição secular e pela natureza da escrita, derivada da China e rica em caracteres, todo escrito apresenta um aspecto estético imediatamente perceptível".

Outro terreno da escrita como invenção é o da experimentação dos artistas verbo-visuais, que empregam livremente as formas gráficas como expressão estética. Uma dessas experimentações é o livro de artista. O livro de artista distingue-se de outros livros por ser suporte para um projeto artístico. Para sua produção, o artista incorpora diversos tipos de materiais, não se restringindo ao papel e à tinta.

Interessa destacar, também, a publicidade como um importante campo de desenvolvimento da escrita como criação. A publicidade, para capturar nossa atenção e fidelização aos produtos, precisa não só inovar os códigos expressivos como também renovar as tipografias gráficas, o que significa criar novas maneiras de escrita e de tipos gráficos. Isso pode ser observado na sequência da publicidade de uma marca, como a Nívea, através dos anos

Para a semiótica discursiva, todo texto é composto por um plano de conteúdo e um plano da expressão. O plano de conteúdo é marcado pelo que o texto diz e o plano de expressão refere-se a como o texto faz para dizer o que diz. O texto publicitário, geralmente, tem seu plano de expressão constituído por elementos de linguagens diversas. Dessa maneira, elementos de diferentes semióticas se relacionam para expressão do conteúdo. Hernandes (2005, p 228) afirma que os "textos publicitários são sincréticos, ou seja, unem várias 
linguagens (ou diferentes formas de expressão, como verbais, musicais, gestuais etc.) para produzir um único 'todo de sentido'."

O objetivo da publicidade é atuar incitando o desejo do destinatário; é instigar um querer e um fazer, fazer querer consumir, fazer com que o consumidor queira e compre. Para tanto, as estratégias de manipulação do criador do anúncio para com o consumidor, destinatário da publicidade, articulam possibilidades de o comover estesicamente por meio dos sentidos, ou seja, de provocar o desejo de comprar através de enunciados que mobilizam visão, audição, tato, olfato e paladar.

Essa intencionalidade comunicativa pode ser observada na campanha da marca Mon Bijou ${ }^{6}$ com o ator Reinaldo Gianecchini, em que o ator vestindo um roupão atoalhado aparece de perfil sentado em uma poltrona reclinável, toda revestida com rolinhos de toalhas, a qual traça uma diagonal do canto superior direito ao canto inferior esquerdo, finalizando com a marca do produto. Ao fundo vemos toalhas empilhadas em diferentes tons de azul. E no canto inferior direito, imagens de diversos produtos da Mon Bijou. A cor azul aparece, aqui, relacionada à maciez, inclusive nos tipos gráficos que parecem dançar em relação à imagem do ator e, em letras pequenas, eles sintetizam a estratégia de manipulação do consumidor - me aperta, me cheira, me chama de Mon Bijou.

Outras práticas de escrita se presentificam em suportes públicos como os grafites e protestos. Petrucci (1999) relaciona tais escritas aos grafites da cidade de Pompeia, às frases devocionais inscritas nos santuários medievais, aos protestos e insultos escritos nas paredes e portas (séculos XVI e XVII) e às escritas de solicitações do movimento operário nos muros das fábricas (fim do século XIX e início do século XX)

No Brasil, um dos exemplos notórios de intervenção escrita na paisagem urbana é o das 56 pilastras pintadas com verde e amarelo pelo profeta Gentileza, no Viaduto do Caju, na cidade do Rio de Janeiro ${ }^{7}$. Elas trazem enunciados que propõem a criação de um mundo melhor, com amor e paz; um mundo no qual gentileza gera gentileza. Tais intervenções sensibilizaram e contagiaram artistas e intelectuais que as retomam para "pregar" a mudança da sociedade pela via da transformação das pessoas. $\mathrm{O}$ escrito transcende o produtor de escrita, e o leitor lhe atribui seus próprios sentidos.

Os enunciadores têm intencionalidade diversa para a produção do objeto escrito em lugares públicos. Tal intencionalidade é orientada por sua história e/ou por seu projeto, por suas motivações, que são tanto individuais como coletivas e que se estabelecem como mobilizadoras do processo criativo. São práticas de escrita em que a palavra é gesto de quem escreve; é a mobilização de experiências corporais para dizer de si, em dado tempo e espaço.

As práticas de escrita têm, assim, um componente autobiográfico que aparece, diretamente ou não, no produto escrito. Ao escrever, o produtor de escrita faz escolhas sobre o que quer tornar público e o que deseja que permaneça no âmbito do privado. Ele se mostra como deseja ser visto; de certa forma, cria uma personagem - uma figura pública que se concretiza na sua escrita. Diante dessa constatação passamos a enfocar a escrita de professores na produção de memoriais de formação.

\section{ESCRITA $^{8}$ : EXPRESSÃo E INVENÇÃo}

Fundamentando-se no pressuposto de que o adulto professor também vive em processo de construção e reconstrução permanente de seus conhecimentos, autores como Nóvoa (2010), Dominicé (2010) e Josso (2004), entre outros, alertam para a urgência de observar os dizeres dos professores sobre sua formação, como modo de apropriação desse processo.

Dominicé (2010) salienta que considerar o percurso biográfico de formação é inserir adultos professores numa perspectiva de educação contínua, em que a trajetória individual não deve dissociar-se de aventuras coletivas. Nesse intuito, escrever sobre esse percurso pode se constituir em oportunidade de devolver à experiência o lugar que merece na aprendizagem de conhecimentos necessários à existência (pessoal, social e profissional).

Em práticas de escrita, os professores buscam construir um sentido próprio para seus estudos e suas trajetórias. Nessas práticas, eles se deparam com o desafio da produção de textos autorais ${ }^{9}$, de se colocarem na escrita como sujeitos de saberes que recriam as rotas ao escrevê-las. Partimos do pressuposto de que, ao escolher e delimitar rotas de seu percurso de formação num texto escrito, o professor, apesar da injunção institucional, exerce a autoria da e na escrita quando constrói os rumos de seu texto e produz, nessa escrita, efeitos de verdade destinados a um enunciatário.

Nessa concepção, os memoriais são textos em que estão enunciadas práticas de constituição de si e de formação docente; textos que trazem escolhas, posicionamentos, experiências significativas selecionadas e tornadas públicas por seus autores nos relatos de suas práticas docentes. $\mathrm{O}$ gênero acadêmico autobiográfico, do qual o memorial faz parte, desde as últimas décadas do século $\mathrm{XX}$, tem-se tornado tradição na universidade brasileira, embora, de acordo com Passegi e Barbosa (2008), já estivesse presente ali desde 1930 como forma de expressão das transformações culturais e acadêmicas. A trajetória do 
gênero memorial nas universidades brasileiras assumiu diferentes características. Conforme salientam Passegi e Barbosa (2008, p. 16), podem-se identificar quatro fases: institucionalização, expansão, diversificação e fundação. "A fase de sua institucionalização, nos anos de 1930, como dispositivo de avaliação para o provimento de cargo de professor catedrático". Já “a fase de sua expansão, quando se generaliza nos anos 1980, com a redemocratização do país, como dispositivo de (auto)avaliação nos processos de ingresso no magistério superior e ascensão funcional". A terceira, "a fase de diversificação, ao assumir uma nova dimensão, a partir de 1990, quando é introduzido como dispositivo de reflexão na formação inicial e continuada de professores como trabalho de conclusão de curso (TCC)". As autoras mencionam que "finalmente, a fase de fundação, nos anos 2000, quando seu uso se intensifica e ele se afirma como objeto de pesquisa, com a "viragem (auto)biográfica' em Educação".

A descrição das fases do percurso do gênero memorial aponta também para a distinção entre memorial acadêmico e memorial de formação. Passegi (2008) caracteriza estes dois tipos de memoriais quanto ao processo de escrita e aos seus propósitos institucionais. Segundo esse autor (p. 106), esta caracterização denomina, "o memorial acadêmico, para designar aqueles que são elaborados por professores e pesquisadores para fins de concurso público, ingresso ou ascensão funcional na carreira docente e/ou para outras funções em instituição de ensino superior"; a denominação memorial de formação serviria "para designar os memoriais escritos durante o processo de formação inicial ou continuada e concebido como trabalho de conclusão de curso no ensino superior (TCC), geralmente, realizado em grupo e acompanhado por um professor orientador".

O memorial, como uma escrita institucional voltada para um processo avaliativo, é marcado por inferências que o distinguem de outros textos autobiográficos. Dessa forma, no campo dos estudos autobiográficos, para clarificar a definição de memoriais, há ainda outra distinção relevante, aquela que estabelece aproximações e diferenças entre memoriais e histórias de vida. Passegi (2008), ao abordar as relações entre histórias de vida e memoriais, esclarece que, no Brasil, a história dos memoriais antecede à história das histórias de vida e formação.

Enquanto as histórias de vida podem abranger a totalidade de uma vida e são produzidas por diferentes grupos de produtores de escrita, os memoriais têm finalidade específica e autores/narradores, pertencentes a grupos mais restritos, que os produzem em contexto determinado. No contexto brasileiro, geralmente, são elaborados por professores e/ou alunos do sistema de ensino superior ${ }^{10}$.

\section{A ESCRITA DA EXPERIÊNCIA E A EXPERIÊNCIA DA ESCRITA}

A escrita de memoriais pressupõe que o sujeito produz e busca refletir sobre o seu saber ao longo do percurso de vida, saber este que está em processo de construção e de reconstrução permanente. Na escrita, o sujeito precisa se referenciar no conhecimento que já possui, compará-lo com o novo que se apresenta e construir sentidos para suas trajetórias. Esse movimento de aprendizagem em/na escrita pressupõe o envolvimento de quem aprende com o objeto de sua aprendizagem.

Nos textos autobiográficos, o que é nomeado passa a ter existência para quem nomeia. Reconhecer trajetórias nomeando-as é ir em busca das memórias, é dar existência ao que fez sentido no percurso, é refletir sobre as vivências, relacionar, produzir singularidades, identificar experiências. Carregamos as vivências na memória; algumas têm intensidade particular que são marcantes e delas é possível extrair informações sobre o que foi observado, percebido e sentido. Elas se impõem à consciência com informações sobre relações consigo e com o entorno. Para Josso (2004), as vivências sobre as quais há reflexão assumem o status de experiências que são significativas na ação de formar-se ${ }^{11}$.

Josso (2004, p. 48) afirma que, na produção do texto, as experiências são significativas em relação ao questionamento que orienta a construção da narrativa. Para que uma experiência seja considerada formadora, ela precisa estar prenhe de aprendizados, isto é, de "atitudes, comportamentos, pensamentos, saber-fazer, sentimentos que caracterizam uma subjetividade e identidades".

A referência à experiência feita por Josso parece remeter ao conceito de experiência educativa em Dewey (2010a), em que o autor considera educativa aquela experiência que possibilita a emergência de outras e com elas se relaciona. Nessa concepção, vida, experiência e aprendizagem são conceitos interligados. Há, portanto, continuidade nas experiências formadoras, que podem ocorrer em diferentes instâncias sociais. Essas relações podem ser retomadas pelos professores na escrita de seus memoriais.

Espera-se que as narrativas de experiências formadoras potencializem a reflexão quando integradas como uma forma de atenção consciente em que o sujeito aprofunda pensamentos sobre si mesmo e sobre sua prática. Josso (2004, p. 257) observa que "a atenção consciente está sempre lá para dar testemunho do mais ou menos longo trabalho de elaboração que gera o movimento do ser para transformações de sentidos, de contextos de vida, de relação com o outro e da relação consigo mesmo". Novamente o que Dewey diz sobre agir e sofrer uma experiência soa como intertexto para as afirmações de 
Josso referentes à atenção consciente. Para Dewey (2010b), a relação entre agir e sofrer a experiência é um trabalho da inteligência que atua de forma consciente.

Aqui cabe outra relação intertextual sobre o conceito de experiência. Para Larrosa (2002), a experiência é aquilo que nos afeta, que nos toca, que produz os rumos no momento mesmo de seu acontecimento. Assim, a experiência escolhida pelo sujeito que escreve é aquela que foi marcante, que fez sentido em seu percurso.

Larrosa, citando Benjamin, ressalta que informação não é experiência; o excesso de informação é quase uma antiexperiência. Larrosa (2002, p. 22) considera que este "sujeito da informação sabe muitas coisas, passa o tempo buscando informação, [...] porém, com essa obsessão pela informação e pelo saber (mas saber não no sentido de 'sabedoria', mas no sentido de 'estar informado'), o que consegue é que nada lhe aconteça".

De acordo com o citado autor, a experiência tem se tornado cada vez mais rara devido à falta de tempo e ao excesso de trabalho. No que se refere ao tempo como impedimento da experiência, tudo ocorre de modo muito rápido e logo é substituído. Estímulos substituem estímulos numa velocidade sem tempo para o silêncio e para a memória em que tudo agita, excita, mas nada acontece.

A afirmação de Larrosa sobre a recepção da experiência pelo sujeito é também uma preocupação nos textos de Dewey quando este afirma que a experiência é percebida de forma diferente, de acordo com o repertório de experiências anteriores do sujeito; este também pode sofrer interferências do ativismo, que produz experiências superficiais ou inconclusas, ou do excesso de receptividade, caso em que o sujeito valoriza somente o passar pelas situações sem parar para significá-las.

Para Dewey, o sujeito da experiência, ao mesmo tempo em que recebe, atua na produção de sentido. Larrosa enfatiza a receptividade e a disponibilidade do sujeito para a experiência: para ele, o sujeito da experiência seria um território de passagem, superfície sensível ao que acontece; ponto de chegada, lugar que recebe o que chega e, ao receber, dá-lhe lugar; espaço onde têm lugar os acontecimentos. Sendo assim, esse sujeito se define não por sua atividade, mas por sua passividade, por sua receptividade, por sua disponibilidade, por sua abertura. Essa passividade é feita de paixão, padecimento, paciência de atenção como uma receptividade primeira, como uma abertura essencial. Conforme Larrosa (2002, p. 25), o sujeito da experiência é aquele que está exposto, "do ponto de vista da experiência, o importante não é nem a posição (nossa maneira de pormos), nem a 'o-posição' (nossa maneira de opormos), mas a 'ex-posição', nossa maneira de 'ex-pormos', com tudo o que isso tem de vulnerabilidade e de risco". E o autor conclui que "por isso é incapaz de experiência aquele a quem nada lhe passa, a quem nada lhe acontece, a quem nada the sucede, a quem nada o toca, nada lhe chega, nada o afeta, a quem nada o ameaça, a quem nada ocorre".

Larrosa (2002, p. 21) sugere, então, um olhar para a educação focado no par experiência/sentido. Ele ressalta que as palavras produzem sentido, criam realidades e podem funcionar como mecanismos de subjetivação. Isso porque "tem a ver com as palavras os modos como nos colocamos diante de nós mesmos e diante dos outros e do mundo em que vivemos". Nomear, dessa forma, é práxis reflexiva sobre o que se é, sobre o que se faz, sobre que se pensa e sente. As palavras que nomeiam coisas tornam presentes os modos de atuar no mundo daquele que nomeia. Dessa forma, as palavras presentificam as relações estabelecidas e os modos de pronunciar o encontro com o outro.

No que tange a nomear a experiência vivida, retomamos, também, as colocações de Merleau-Ponty (1991) quando se refere às metamorfoses do pensamento em palavras e das palavras em pensamento para acrescentar que, na práxis da escrita, o eco das palavras vem de toda parte. A fala com o outro é, ao mesmo tempo, uma fala consigo mesmo. Assim, nomear algo é uma atividade de intersubjetividade, em que os sentidos individuais são produzidos numa relação com os significados coletivos.

\section{NARRATIVAS E FORMAÇÃO}

Em que consiste, então, a experiência narrativa que fundamenta os textos autobiográficos? O lugar que a narrativa tem assumido na formação de professores e na produção de textos sobre formação decorre especialmente da condição humana de fabulação. Para a espécie humana, contar história foi e é a forma encontrada de atribuir sentido à experiência vivida e de construir explicações ou previsões que projetem novas experiências. Tal condição possibilitou a sobrevivência, criação e recriação da cultura.

Como escreve Huston (2010), “apenas nós percebemos a nossa existência terrestre como uma trajetória dotada de sentido (significação e direção). Um arco. Uma curva que vai do nascimento à morte. Uma forma que se desdobra no tempo com um início, peripécias e um fim". A autora sintetiza dizendo que se trata de uma narrativa, a qual se tornou um modo de sobrevivência entre os humanos. A narratividade "está inscrita nas próprias circunvoluções do nosso cérebro. Mais fraco do que os outros grandes primatas, ao longo de milhões de anos de evolução, o Homo Sapiens entendeu o interesse vital que teria em dotar, através das suas fabulações, o real de Sentido".

Como humanos e como professores, inventamos histórias e criamos imagens de nós mesmos para nós 
mesmos, para o outro, para os grupos em que transitamos; imagens que se transformam e que se multiplicam ao longo da vida; dimensões dos nossos modos de presença no mundo. Cornnely e Clandinin (1995, p. 11-12) enunciam a relação entre a fabulação humana e o papel que as narrativas vêm assumindo nos processos de educação de alunos e professores, ao afirmarem que é através da narrativa que experimentamos o mundo. Sua tese é que "la educación es la construción y la reconstrucción de historias personales y sociales; tanto los profesores como los alumnos son contadores de historias y también personajes en las historias de los demás y en las suyas propias".

Para esses autores, os humanos contam histórias e vivem vidas relatadas e, por isso, no campo das ciências sociais $^{12}$, a narrativa pode ser assumida tanto como fenômeno a ser investigado quanto como método de investigação. Nas ciências sociais, narrativa é tanto a estrutura que se toma para dizer da experiência quanto o meio que se utiliza para o estudo das variadas experiências.

A arte da narrativa é abordada por Walter Benjamin no ensaio $O$ narrador (1987, p. 198), em que considera que narrar é intercambiar experiências. Para ele, "a experiência que passa de pessoa a pessoa é a fonte a que recorrem todos os narradores". Há dois tipos fundamentais de narradores: aquele que viaja muito, que vem de longe, e aquele que nunca deixou o seu país, que sabe as histórias de suas tradições. A arte da narrativa é entendida na relação que se estabelece entre estes dois tipos - o sedentário e o viajante. Para narrar, há que se viajar; é preciso sair do ambiente próximo e inventar novas terras, mas é preciso também fazer tal percurso consciente de suas tradições, de suas implicações culturais. As experiências são evocadas no movimento entre próximo e distante, conhecido e desconhecido, semelhante e diferente. Benjamin (1980, p. 62), referindo-se a Nikolai Leskov como um narrador que sintetiza os tipos fundamentais, diz que "seu ideal é o homem que aceita o mundo sem se prender demasiadamente a ele". Nessa perspectiva, as narrativas são inseparáveis das práticas culturais.

Abrahão (2011), ao comentar a relação entre narrativas e escrita de memoriais de formação, afirma que a tessitura de um memorial exige mais que um relato de momentos da história de vida; é necessária uma narrativa orgânica e reflexionada de acontecimentos em contexto. Trata-se não do relato dos fatos em si, mas da atribuição de sentido ao que foi vivido por meio da produção do texto escrito. A autora alerta para a relevância da clarificação do conceito de memória no entendimento dos processos de produção dos memoriais e considera que a memória é reconstrutiva, criativa e seletiva, isto é, no ato da escrita autobiográfica, o sujeito significa e seleciona fatos que deseja narrar; ele os organiza em uma sequência reconfigurando, recriando memórias e criando metamemórias. Metamemória é entendida como produto da reflexão sobre a própria memória, ato que é permeado por crenças, sentimentos e significados que influenciam a atribuição de sentido à experiência narrada.

Abrahão (2011) acrescenta que, para memorizar fatos, é preciso que eles tenham evocado emoções no sujeito. Essa afirmação remete ao papel atribuído por Dewey à emoção na experiência educativa. Conforme o autor, a emoção é o que colore a experiência, isto é, a emoção pode gerar significados e transformar o curso dos acontecimentos. A emoção concorre para que a experiência siga seu fluxo até chegar a uma consumação e, dessa forma, para que a experiência assuma uma dimensão estética. É a emoção que possibilita o relacionamento entre os fatos, permitindo que uma experiência se estabeleça como possibilidade para outras

A flexibilidade e reelaboração da memória atribuem sentido aos acontecimentos nas práticas narrativas transitando em um tempo que relaciona passado, presente e futuro. Abrahão (2011, p. 166), referindo-se à perspectiva do tempo narrativo como o relacionamento entre os aspectos fenomenológico e cronológico, afirma que essa percepção do tempo acaba por marcar a atividade narrativa com uma não linearidade. Segundo a autora, esta natureza "temporal tridimensional da narrativa, tendo em vista que esta rememora o passado com os olhos do presente e permite prospectar o futuro, é razão pela qual o próprio discurso narrativo não procura necessariamente obedecer a uma lógica linear e sequencial".

Discini (2005) salienta que o tempo tripartido da narrativa é um atributo humano de criação de efeitos de presença que, no texto autobiográfico, fomenta um jogo de parecer/ser do sujeito que se coloca como enunciador de suas experiências. Tais elaborações sobre a presença que se enuncia no texto ensejam questionamentos sobre a concepção de verdade narrativa.

$\mathrm{Na}$ leitura e/ou escrita de textos, o sujeito se investe da relação fiduciária, isto é, escreve intencionalmente para mobilizar algo ou alguém. Como ressaltam Greimas e Courtés (2008, p. 208-209), estabelece-se um contrato fiduciário no qual o destinador propõe um fazer persuasivo e o destinatário adere a este fazer. Assim, "se o objeto do fazer persuasivo é a veridicção (o dizer-verdadeiro) do enunciador, o contra-objeto, cuja obtenção é esperada, consiste em um crer-verdadeiro que o enunciatário atribui ao estatuto do discurso-enunciado".

Fidúcia e veridicção são noções que auxiliam na análise de discursos na semiótica discursiva, pois, para essa abordagem teórica, o discurso cria um mundo fictício. Não existe $a$ verdade, mas efeitos de verdade ensejados por quem escreve, os quais serão (re)significados pelo leitor. Assim, veridicção e fidúcia são elementos do ato 
enunciativo. $\mathrm{O}$ enunciador procura criar efeitos de verdade no texto, isto é, instala no texto um discurso veridictório para seduzir, convencer o enunciatário. $\mathrm{O}$ enunciatário (leitor) pode interpretar e se deixar envolver pelo texto, o que o leva ao estabelecimento de um contrato fiduciário (MENDES, 2011).

A narrativa biográfica, segundo Ferraroti (2010), não é um relatório de acontecimentos tal qual o ocorrido. A narrativa não conta uma vida; ela narra uma interação presente por meio de uma vida e cria uma verdade biográfica.

Para construir sentidos sobre as experiências narradas em memoriais a respeito de sua formação, os professores vivenciam duas ordens de manifestações de sentido: os textos e as práticas. De acordo com Landowski (2001), textos e práticas empiricamente são gêneros de objetos diferentes: cada um faz sentido, mas não da mesma maneira. O desafio da escrita, neste caso, foi o de construir formas de falar sobre as práticas, desafio de criação de um metadiscurso sobre o processo de (auto)formação. Nessa criação do dizer ${ }^{13}$, o professor busca construir um sentido próprio para seus estudos e trajetórias, o que requer seu envolvimento singular com o objeto de sua aprendizagem. Landowski (2005, p. 14) salienta que "é somente ao enunciar - ao fazer surgir sentido por seus atos semióticos, qualquer que seja a natureza (falar, gesticular, ou, ao invés, suspender o gesto, o movimento ou a fala) que os sujeitos se constroem eles próprios, construindo o mundo enquanto significante".

Mas, como perceber e analisar a presença da dimensão estética nas narrativas escritas dos professores sobre seu processo de formação e suas propostas em linguagens artísticas para crianças?

O caminho para a abordagem da dimensão estética foi o da análise dos memoriais, olhando pelo ângulo do regime de sentido da união (LANDOWSKI, 2005). Na união, a significação é produzida no encontro entre corpos condutores de sentido, dotados de competência estésica que entram em contrato com outros objetos e sujeitos dotados de consistência estésica, isto é, de qualidades sensíveis oferecidas à percepção.

As interfaces entre experiência estética, ensino e arte também serviram de norte para a leitura dos textos dos professores. As narrativas de experiências encontradas nos memoriais convergem na ênfase em alguns aspectos, mas são compostas também por particularidades que singularizam o percurso de cada autor.

Lourdes Vitor (2007) inicia seu memorial ressaltando sua experiência com a cidade em que nasceu, uma cidade pequena do estado do Rio Grande do Norte que fica "acima do nível do mar e do resto do país" (VITOR, 2007, p. 12). Tal afirmação transporta o leitor para o cenário do interior do Rio Grande do Norte, no início da década de
1970, com ruas pacatas repletas de crianças brincando livremente. $\mathrm{O}$ encontro estésico é narrado como interação sujeito-mundo à medida que Lourdes descreve sons, cores, sabores e texturas para caracterizar o ambiente de sua infância e tecer relações entre essas experiências e seus projetos futuros. Lourdes faz referência ao distanciamento da cidade do resto do país para dizer de um contexto em que as experiências de formação profissionais são limitadas. Diante de tal limitação, ela vai urdindo sua história e tecendo projetos, seguindo trilhas e mudando de rumo de acordo com os desafios que o contexto the apresenta. Ela afirma ter sido atleta quando adolescente, ao mesmo tempo que participava de um grupo de teatro de sua cidade. Como escolha profissional, por falta de outras opções, torna-se professora, e é como professora que irá articular as experiências anteriores para significar a sua formação. Assim, no texto de Lourdes Vitor (2007) os projetos de vida e formação acionam as linguagens tanto da Arte quanto da Educação Física. Ela se constitui como professora em interação com as duas áreas. Enfatiza a cultura de movimento como campo de conhecimento que comporta as interfaces pretendidas por ela. A formação como atriz é articulada a sua prática docente. Quando trata do trabalho com crianças, prioriza a interdisciplinaridade e o diálogo como fundamentais na sua atuação. A autora relaciona suas experiências estésicas e estéticas com a arte circense, na infância e em oficina de teatro, aos interesses das crianças para transformar esse tema em projeto didático.

$\mathrm{Na}$ narrativa de Margreth Albuquerque (2007) a relação entre linguagens artísticas e a arte literária a conduz à escolha da literatura de cordel como prática de linguagem a ser apresentada às crianças. A preferência pela arte literária é decorrente das experiências da autora com esse conteúdo/linguagem desde a infância. Ela faz o relato de situações e contextos prazerosos de acesso ao repertório cultural da literatura como leitora, ao mesmo tempo que, como professora, organiza experiências educativas que propiciem às crianças o prazer do contato com os textos. As experiências de infância com o gênero cordel são atualizadas pela professora quando esta articula um projeto didático cuja intencionalidade é a de aproximar as crianças da literatura de cordel. Para tanto, ela organiza momentos de leitura dos cordéis em sala de aula. Descrevendo essas situações, Margreth trata do seu envolvimento corporal com o texto referindo-se aos gestos e entonação da voz que são necessários para contagiar as crianças e despertar o interesse pelo texto em cordel. Na narrativa das experiências de leituras propostas às crianças, é perceptível a preocupação de Margreth com as formas de expressão (verbal - oral e escrita - e arte literária) que são características do tipo de texto em foco. Além das rodas de leitura, ela traz, para ser 
entrevistado pelas crianças, Antônio Francisco, cordelista de sua região que é o substituto de Patativa do Assaré na Academia Brasileira de Literatura de Cordel. Assim, no relato de Margreth Albuquerque as práticas e atividades de linguagens são vivenciadas tanto pela professora como pelas crianças buscando as interfaces entre a linguagem verbal oral e/ou escrita e a arte literária de sua região.

O texto de Graças Pinheiro (2007) traz o brinquedo cantado como experiência com linguagens artísticas na infância e o ensino de música e dança como uma vivência de escolarização. Tal destaque é intercalado pela narrativa de suas primeiras memórias de infância onde enfatiza o contato com o som da voz da mãe cantando para embalar o seu sono. No entanto, o projeto desenvolvido por Graças com seus alunos tem como foco o processo criativo de Frans Krajcberg. A escolha do tema meio ambiente está relacionada ao projeto pedagógico da escola, mas as formas de expressão através das linguagens artísticas com esculturas a partir de elementos da natureza, bem como a ênfase na temática da criatividade, arte e meio ambiente é uma opção dessa professora.

Josefa Sousa (2007) trata, entre outros assuntos, da articulação entre as experiências das crianças fora dos muros da escola e a prática docente. Salienta que o brincar é a prática corporal mais exercida pelas crianças, traz relatos de sua infância sobre brincadeiras e brinquedos e faz levantamento das brincadeiras das crianças no bairro em que trabalha. Essa autora diversifica os seus estudos sobre práticas corporais quando apresenta às crianças a dança dos Caboclinhos do Rio Grande do Norte. A justificativa para tal escolha é a de favorecer o acesso das crianças ao rico acervo da cultura do Rio Grande do Norte.

Maurício Medeiros (2007) localiza na região de serras, que rodeiam a cidade onde nasceu, cavernas com pinturas rupestres. A leitura que faz das imagens da sua ambiência de infância é levada para sala de aula e apresentada às crianças. Para contagiar as crianças com o tema das pinturas rupestres do Rio Grande do Norte, o professor articula intencionalmente formas de expressão próximas às práticas de linguagens das crianças, tais como contação de histórias, brincadeiras, desenhos e pinturas em suportes amplos. O conteúdo que o professor trabalha deixa visível para as crianças que está interligado às formas de expressão que ele articula para tornar as pinturas rupestres significativas para o grupo.

Ao tratar a mediação dos professores para possibilitar o acesso das crianças às linguagens artísticas, constatamos que as experiências estéticas e estésicas relatadas nos memoriais dos professores permearam as formas de expressão utilizadas (teatro e arte circense; literatura; esculturas com elementos da natureza; dança; desenho, pintura) como estratégias de ensino importantes para provocar o contágio das crianças pelos conteúdos/ linguagens da arte.

As culturas da infância, culturas escolares, culturas das famílias e culturas da comunidade são tematizadas pelos professores com o objetivo de estabelecer um diálogo entre os diferentes repertórios estéticos e artísticos que atravessam tais instâncias sociais. Os critérios de escolha dos conteúdos/linguagens artísticas consideram o diálogo entre culturas e o interesse das crianças pelos temas. Desse modo, a relação entre experiência estética e cultura é fundamental para a articulação dos processos de ensino e aprendizagem.

\section{CONSIDERAÇõES FINAIS}

O ato de escrita é também de leitura; é leitura das práticas, da seleção dos momentos significativos, da decisão sobre o percurso, da reflexão para entendimento das práticas, das considerações que podem promover o reconhecimento daquilo que moveu ou que move as escolhas. É no entrelaçamento entre intencionalidade e sensibilidade que a escrita é produzida.

Assim, se tomarmos a semiótica discursiva como referencial de leitura de práticas e textos, poderemos voltar o olhar para as situações em que, na escrita, os professores enunciam ${ }^{14}$ experiências estésicas e estéticas. Como esses sujeitos da enunciação, produtores de suas narrativas de formação, enunciadores, ao mesmo tempo em que enunciatários ${ }^{15}$ se dizem por escrito? Como relatam o encontro com objetos/sujeitos do cotidiano e/ ou da arte que lhes possibilita olhares estéticos?

Deste modo, ao escrever ou ler, o sujeito lida com camadas diferentes de produção de sentido e relações internas e externas ao texto. O sentido do qual falamos, ao pensar sobre o operador de escrita e/ou leitor do texto, refere-se à expressão escrita do "sentido sentido" - sentido-sensação e sentido-significação, processo de significação que tem como matriz inicial a percepção estésica em que sensível e inteligível são dimensões constitutivas de apreensão do real.

Escrever sobre o vivido é uma forma de pensá-lo em relação às configurações objetivas inscritas no mundo. De acordo com Landowski (2002), aquele que escreve sobre sua experiência é alguém marcado por configurações objetivas, contextuais e relacionais. Para transformar o que foi vivido em escrita, faz-se necessário traçar um caminho pessoal e entender o próprio ato de traçar.

Conforme Landowski (2010), a escrita pode ser uma operação criadora em que é preciso compreender a relação entre o criador e o objeto. $\mathrm{O}$ criador - redator ao produzir um texto - não realiza unicamente operações pragmáticas de justaposição de marcas sobre o papel. Escrever é, às vezes, ir além do que a linguagem oferece, isto é, a escrita 
pode produzir um objeto - texto que reconfigura o mundo e a linguagem. Portanto, a escrita do memorial de formação se constituiu, para os professores, em experiência de significação de seus encontros estésicos e estéticos, bem como em oportunidade de refletir sobre os rumos de seus projetos de formação e sobre a intencionalidade de sua prática docente.

\section{REFERÊNCIAS}

ABRAHÃO, Maria Helena Menna Barreto. Memoriais de formação: a (re)significação das imagens-lembranças/ recordações/referências para pedagoga em formação. Educação, Porto Alegre, v. 34, n. 2, p. 165-172, maio-ago. 2011.

ALBUQUERQUE, Maria Margreth Freire. Lembranças de minhas leituras: o despertar prazeroso pela arte literária. (Memorial descritivo de Formação - Curso de Especialização em Ensino de Arte e Educação Física na Infância). 2007. Universidade Federal do Rio Grande do Norte, Mossoró, RN.

BAKHTIN, Mikhail. Estética da criação verbal. Tradução de Maria Ermantina Galvão G. Pereira. 2. ed. São Paulo: Martins Fontes, 1997.

BENJAMIN, Walter. O narrador: observações sobre a obra de Nikolai Leskov. In: Walter Benjanin. São Paulo: Abril Cultural, 1980. p. 57-74. (Coleção Os pensadores, v. 1 e 4).

BENJAMIN, Walter. O narrador: observações sobre a obra de Nikolai Leskov. In: BENJAMIN, Walter. Magia, arte, técnica e política. São Paulo: Brasiliense, 1987. p. 197-221.

CAÑIZAL. Eduardo Peñuela. A metáfora da intertextualidade. In: BARBOSA, Ana Mae; FERRARA, Lucrécia D'Aessio; VERNASCHI, Elvira (Org.). O ensino de artes nas universidades. São Paulo: Edusp, 1993. p. 77-89.

CERTEAU, Michel de. Ler: uma operação de caça. In: CERTEAU, Michel de. A invenção do cotidiano: 1 Artes de fazer. Petrópolis: Vozes, 1994. p. 259-270.

CORNNELLY, F. Michael; CLANDININ, D. Jean. Relatos de experienciar y investigación narrative. In: LARROSA, Jorge. Déjame que te cuente: ensayos sobre narrativa y educación. Barcelona: Laertes, 1995. p. 11-59.

DEWEY, John. Experiência e educação. Petrópolis: Vozes, 2010a.

DEWEY, John. Arte como experiência. Tradução de Vera Ribeiro. São Paulo: Martins Fontes, 2010b.

DISCINI, Norma. Das vicissitudes do sujeito. Todas as Letras, ano 7, n. 2, 2005.

DOMINICÉ, Pierre. A biografia educativa: instrumento de investigação para educação. In: NOVOA, Antônio; FINGER, Matthias (Org.). O método (auto)biográfico e a formação. Natal: EDUFRN; São Paulo: Paulus, 2010. p. 143-153.

FERRAROTI, Franco. Sobre a autonomia do método biográfico. In: NÓVOA, Antonio; FINGER, Matthias (Org.). O método (auto)biográfico e a formação. Natal: EDUFRN; São Paulo: Paulus, 2010. p. 30-57.

FOUCAULT, Michael. O que é um autor? In: FOUCAULT, Michael. Estética: literatura, e pintura, música e cinema. Rio de Janeiro: Forense Universitária, 2006. p. 264-298. (Coleção Ditos e Escritos, 3)
GREIMAS, A. J.; COURTÉS, J. Dicionário de semiótica. São Paulo: Contexto, 2008.

HERNANDES, Nilton. Duelo: a publicidade da tartaruga da Brahma na Copa do Mundo. In: LOPES, Ivã Carlos; HERNANDES, Nilton (Org.). Semiótica: objetos e práticas. São Paulo: Contexto, 2005. p. 227-244.

HUSTON, Nancy. A espécie fabuladora: um breve estudo sobre a humanidade. Porto Alegre: L\&M, 2010.

JOSSO, Marie-Christine. Experiência de vida e formação. São Paulo: Cortez, 2004.

JOSSO, Marie-Christine. Da formação do sujeito... Ao sujeito em formação. In: NÓVOA, Antonio; FINGER, Matthias (Org.). O método (auto)biográfico e a formação. Natal: EDUFRN; São Paulo: Paulus, 2010. p. 59-79.

JOSSO, Marie-Christine. O corpo biográfico: corpo falado e corpo que fala. Educação \& Realidade, Porto Alegre, v. 37, n. 1. p. 19-31, jan.-abr. 2012.

KAHLO, Frida. O diário de Frida Kahlo: um auto-retrato íntimo. Rio de Janeiro: José Olympio, 1996.

LANDOWSKI, Eric. O olhar comprometido. Revista Galáxia, São Paulo, n. 2, p. 19-56, 2001.

LANDOWSKI, Eric. Presenças do outro. São Paulo: Perspectiva, 2002.

LANDOWSKI, Eric. Aquém ou além das estratégias, a presença contagiosa. Documentos de Estudo do Centro de Pesquisas Sociossemióticas, São Paulo, n. 3, 2005.

LANDOWSKI, Eric. Avoir prise, donner prise. Documento do Centro de Pesquisa Sociosemiótica (CPS), São Paulo, 2010

LARROSA, Jorge. Notas sobre a experiência e o saber da experiência. Revista Brasileira de Educação, Rio de Janeiro, n. 19, p. 20-28, jan.-abr. 2002.

MEDEIROS, Maurício José de. Memórias das imagens do tempo: (re)desenhando relatos de experiências exitosos. (Memorial descritivo de Formação - Curso de Especialização em Ensino de Arte e Educação Física na Infância). 2007. Universidade Federal do Rio Grande do Norte, Natal, RN.

MENDES, Mariza Bianconcini Teixeira. Capitu entre dois enigmas: veridicção e fidúcia. Estudos Semióticos, São Paulo, v. 7, n. 1, p. 56-67, jun. 2011. Disponível em: <www.fflch.usp. br/semiótica/es>. Acesso em: abr. 2012.

MERLEAU-PONTY, Maurice. Signos. Tradução de Maria Ermantina Galvão Gomes Pereira. São Paulo: Martins Fontes, 1991.

NERUDA, Pablo. Livro das perguntas. São Paulo: Cosac Naify, 2008.

NÓVOA, Antônio; FINGER, Matthias (Org.). O método (auto) biográfico e a formação. Natal: EDUFRN; São Paulo: Paulus, 2010

PASSEGI, Maria da Conceição. Memoriais: injunção institucional e sedução autobiográfica. In: PASSEGI, Maria da Conceição; SOUZA, Elizeu Clementino (Org.). (Auto) biografia: formação, territórios e saberes. Natal: EDUFRN; São Paulo: Paulus, 2008, p. 103-131.

PASSEGI, Maria da Conceição; BARBOSA, Tatiana Mabel Nobre (Org.). Memórias, memoriais: pesquisa em formação docente. Natal: EDUFRN; São Paulo: Paulus, 2008. 
PETRUCCI, Armando. Escritura como invención, escritura como expresión. In: PETRUCCI, Armando. Alfabetismo, escritura, sociedad. Barcelona: Gedisa, 1999. p. 171-180.

PINHEIRO, Maria das Graças Bezerra. História vital. (Memorial descritivo de Formação - Curso de Especialização em Ensino de Arte e Educação Física na Infância). 2007. Universidade Federal do Rio Grande do Norte, Parnamirim, RN.

SCHNEUWLY, Bernard; DOLZ, Joaquim. Gêneros orais e escritos. Campinas SP: Mercado das Letras, 2004.

SOUSA, Josefa Jeane Gomes. Entre o saber, o buscar e o fazer: trajetória e perspectiva de uma formação. (Memorial descritivo de Formação - Curso de Especialização em Ensino de Arte e Educação Física na Infância). 2007. Universidade Federal do Rio Grande do Norte, Natal, RN.

TFOUNI, Leda Verdiani. Letramento e alfabetização. São Paulo: Cortez, 2002.

TFOUNI, Leda Verdiani (Org.). Múltiplas faces da autoria. Ijuí: Editora Unijuí, 2008.

VITOR, Maria de Lourdes. Cenas da vida de uma educadora construída com: arte, teoria e movimentos. (Memorial descritivo de Formação - Curso de Especialização em Ensino de Arte e Educação Física na Infância). 2007. Universidade Federal do Rio Grande do Norte, Parnamirim, RN.

\section{NOTAS}

1 O termo escritura é usado neste texto para falar sobre as práticas sociais que ampliam o entendimento de escrita para além da grafia de letras, incluindo as relações de produção que envolvem essa prática. Por exemplo, as relações com a oralidade e com a visualidade que se fazem presentes no texto escrito. Para mais informações sobre o conceito de escritura, ver Schneuwly e Dolz (2004).

2 O Livro das perguntas foi publicado no Brasil, em 2008, pela Cosac\&Naify, com tradução de Ferreira Gullar Fonte: NERUDA, 2008. Disponível em: <http://www.livrariacultura.com.br/scripts/resenha/ resenha.asp?nitem $=11019697 \&$ sid $=18927311211519709352756660 \& \mathrm{k}$ 5=DD7AA7B\&uid=>. Acesso em: 27 abr. 2010.

3 Os poemas do diretor do filme - Peter Greenaway - são escritos no corpo da atriz em japonês.

4 Disponível em: <http://www.cineplayers.com/filme.php?id=965>. Acesso em: 24 maio 2011.

5 Sodô, arte da caligrafia japonesa - $\mathrm{O}$ evento, que acontece anualmente em Tóquio, celebra o Ano-Novo. Os mais de 3.000 participantes tiveram que escrever, em 24 minutos, os desejos para 2011, usando caracteres japoneses. Um dos critérios da competição de caligrafia era o de escrever o ideograma em uma única pincelada. Disponível em: $<$ http:// noticias.r7.com/videos/concurso-de-caligrafia-reune-mais-de-3-000participantes-no-japao-/idmedia/ed9da4c1e62a694259c2147277638cb7. html $>$. Acesso em: 8 nov. 2011.

6 Disponível em: <:http://www.google.com.br/search?hl=pt-anu_bombril_ mon bijou gianecchini dpz 1007.jpg >. Acesso em: 24 maio 2011.

7 Disponível em: <http://dezine411.wordpress.com/2010/12/03/97/>. Acesso em: 28 maio2011.
8 A partir deste momento passamos a usar o termo escrita para tratar do texto verbal escrito, mais especificamente.

9 O conceito de autoria é discutido por autores como: Foucault (2006), Bakhtin (1997), Tfouni (2002 e 2008).

${ }^{10}$ Passegi (2008, p. 125) tece comentários sobre a injunção institucional na escrita de memoriais: "Narrar, refletindo sobre o que se fez, é uma prática humana, mas fazê-lo dentro de modelos narrativos próprios em uma esfera cultural é algo que se adquire na relação com seus membros. O memorial, tal como se pratica atualmente, pode ser percebido como uma tentativa de objetivação da escrita subjetiva ou uma subjetivação do discurso objetivo. Sua dimensão avaliativa tenderia a direcionar o narrador a assumir o papel social, regulando sentimentos de pertença ao grupo social com o qual deve/pode interagir".

11 A palavra "formação" apresenta dificuldade semântica, pois designa tanto a atividade no seu desenvolvimento temporal como o respectivo resultado (JOSSO, 2010, p. 61). "Formar-se" aqui é usada como processo de formação do ponto de vista do sujeito.

${ }^{12}$ Estudo de caso, história de vida, psicanálise, literatura, estudos da linguagem, estudos de gênero, investigação sobre o desenvolvimento infantil, histórias de vida de grupos específicos, como, por exemplo, os professores, entre outras.

13 “'[...] toda exploração do mundo, toda 'viagem', enquanto experiência da relação com um aqui-agora sem cessar redefinível, equivale a um processo de construção do eu (LANDOWSKI, 2002, p. 71).

${ }^{14}$ Enunciação - “[...] se definirá de duas maneiras diferente: seja como estrutura não linguística (referencial) que subtende à comunicação linguística, seja como uma instância linguística, logicamente pressuposta pela própria existência do enunciado (que dela contém traços e marcas). No primeiro caso, falar-se-á de 'situação de comunicação', de contexto 'psicossociológico' da produção dos enunciados, que tal situação (ou contexto referencial) pode atualizar. No segundo caso, sendo o enunciado considerado o resultado alcançado pela enunciação, que aparece como a instância de mediação, que assegura a colocação em enunciado-discurso das virtualidades da língua. De acordo com a primeira acepção, o conceito de enunciação tenderá a aproximar-se do de ato de linguagem, considerado sempre na sua singularidade; de acordo com a segunda, a enunciação é concebida como um componente autônomo da teoria da linguagem, como uma instância que possibilita a passagem entre a competência e a performance (linguística entre estruturas semióticas virtuais de cuja atualização ela deve encarregar-se, e as estruturas realizadas sob a forma de discurso" (GREIMAS; COURTÉS, 2008, p. 166).

15 Enunciador/Enunciatário - A estrutura da enunciação, considerada como quadro implícito e logicamente pressuposto pela existência do enunciado, comporta duas instâncias: a do enunciador e a do enunciatário. Denominar-se-á enunciador o destinador implícito da enunciação (ou da "comunicação"), distinguindo-o assim do narrador - como o "eu", por exemplo - que é um actante obtido pelo procedimento de debreagem, e instalado explicitamente no discurso. Paralelamente, o enunciatário corresponderá ao destinatário implícito da enunciação, diferenciando-se, portanto, do narratário (por exemplo: "o leitor compreenderá que..."), reconhecível como tal no interior do enunciado. Assim compreendido, o enunciatário não é apenas destinatário da comunicação, mas também sujeito produtor do discurso, por ser "leitura" um ato de linguagem (um ato de significar) da mesma maneira que a produção do discurso propriamente dito. O termo 'sujeito da enunciação', empregado frequentemente como sinônimo de enunciador, cobre de fato as duas posições actanciais de enunciador e de enunciatário (GREIMAS; COUTÉS, 2008, p. 171).

Artigo recebido em julho 2014

Aprovado em outubro 2014. 